\title{
Buerger Exercise Reduces the Risk of Neuropathy in People with Diabetes Mellitus
}

\author{
Laily Hidayati ${ }^{1} \mathbb{D}$, Ika Nur Pratiwi ${ }^{1 *} \mathbb{D}$, Zulfayandi Pawanis ${ }^{2} \mathbb{D}$, Lisa McKenna ${ }^{3}$, Ika Yuni Widyawati ${ }^{4}$ \\ ${ }^{1}$ Department of Fundamental Nursing, Faculty of Nursing, Universitas Airlangga, Surabaya, Indonesia; ${ }^{2}$ Department of Surgery, \\ Universitas Airlangga Hospital, Universitas Airlangga, Surabaya, Indonesia; ${ }^{3}$ Department of Nursing and Midwifery, College of \\ Science Health and Engineering, La Trobe University, Bundoora, VIC, Australia; ${ }^{4}$ Department of Advanced Nursing, Faculty of \\ Nursing, Universitas Airlangga, Surabaya, Indonesia
}

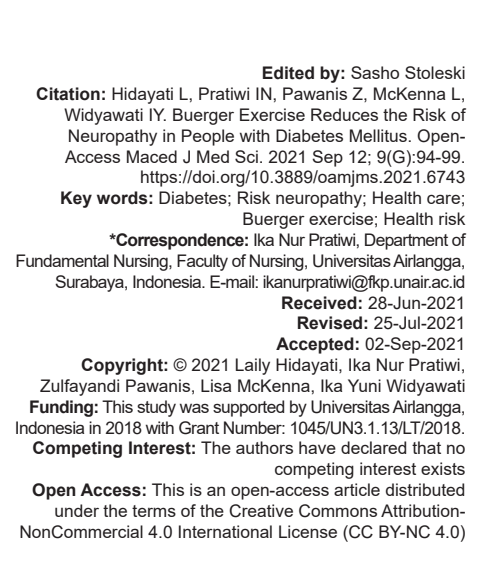

\section{Abstract}

BACKGROUND: Diabetes mellitus (DM) remains the major global health problem, predicted to exceed half a billion people in 2040. One of the major complications was lower extremity neuropathy leading to foot ulcer and amputation. AIM: This study aimed to investigate the effect of routine Buerger exercise (BE) on the neuropathy index of people with DM. METHODS: A pre- and post-test quasi-experimental study between May and August 2018 involving DM patients in primary health center was conducted. They were prospectively recruited and either be allocated into the intervention group where the monitored routine BE was performed or control group with the standard education on DM. Michigan Neuropathy Screening Instrument (MNSI) with subjective and objective measurement was used to evaluate the neuropathy index.

RESULTS: Seventy-seven participants (63 females) with a mean age of $58.2 \pm 7.2$ years completed the study with similar characteristics. Mean pre-test MNSI score for intervention and control group was $3.8 \pm 1.7$ and $3.9 \pm$ 1.6 , respectively, and was not different $(p=0.561)$. At the end of follow-up, significant decrease was observed in the intervention group $(2.8 \pm 2.2, p=0.011)$ but not in control group $(4.0 \pm 1.9, p=0.947)$. Physical examination according to $\mathrm{MNSI}$ guideline showed a significant reduction in the neuropathy score for the intervention group from $1.8 \pm 1.4$ at the start to $1.3 \pm 1.1$ at the end of the study $(p<0.001)$, but this was not seen in the control group.

CONCLUSION: BE had a beneficial effect on improving the neuropathy index and symptoms of DM patients with high risk of diabetic foot ulcer.

\section{Introduction}

Diabetes mellitus (DM) is a threat to the health of society because it can cause a range of chronic health problems. It is predicted that the prevalence of DM will continue to increase in the upcoming years [1]. The International Diabetes Federation in estimated that 463 million people have diabetes globally and predicted to reach 578 million in 2030 [2]. Indonesia as one of the fifth most populous countries also has the problem with diabetes. According to the national basic health survey in 2018, there were about $1.5 \%$ of Indonesian which have diabetes and one of the provinces with prevalence above the national average was East Java Province (2\% prevalence) [3].

One of the common complications of diabetes is lower extremity circulatory compromise leading to foot ulcer [4]. It is estimated that $25 \%$ of people with diabetes will experience at least one related foot ulcer during their lives, and that $90 \%$ of whom would require lower limb amputation [5]. The main causes are occlusion of peripheral arteries and neuropathy, with the latter being the major contributor to sensory loss of the lower limb in patients with DM [6].
The core management of DM remains the regulation of blood glucose through various approaches including programmed education to improve medication adherence, physical activity, regular monitoring, and diet modification [7], [8], with the addition of foot care to prevent the occurrence of foot ulcers. Specific exercises for feet and ankles were included in the Guideline of the International Working Group on the Diabetic Foot in 2019 for the treatment of modifiable factors for the development of ulcers [9]. Buerger exercise (BE) is one of the self-administered exercises that can be performed at the convenient time. It may help improving peripheral neuropathy symptoms, improve skin perfusion pressure and peripheral circulation [10].

BE with promotional programs in type 2 DM health could reduce symptoms of peripheral neuropathy and improve peripheral circulation. In BE, a gravitational force is applied, non-invasive therapy that is easily learned and performed daily at home [11]. This study aimed to investigate the effect of routine BE to reduce the risk of neuropathy people with DM. 


\section{Methods}

\section{Design and sample}

This study sought to examine the impact of $\mathrm{BE}$ to reduce the risk of neuropathy of people with type $2 \mathrm{DM}$ in the community setting using a quasiexperimental design with treatment and control group. Participants were included into the study if they satisfied the following inclusion criteria:

1. Had been diagnosed as type 2 DM by a general practitioner at the primary health center

2. Age under 80 years

3. Able to communicate verbally and were literate

4. Not hospitalized or in critical condition.

Recruitment process was started by prospectively enrolling patients at the primary health center between May and August 2018.

After baseline data were obtained, participants were then selected into control and treatment group based on the matching process. Matching was done using the baseline characteristics of age, education, employment, income level, and location of residence.

At the start of the study, in addition to baseline data collection, all participants were also assessed for their risk of having diabetic neuropathy using the Michigan Neuropathy Screening Instrument (MNSI) which includes history of disease and a series of physical examinations such as $128 \mathrm{~Hz}$ tuning fork test for vibration sensation and $10 \mathrm{~g}$ monofilament test, as have been described in detail elsewhere [12], [13]. At the end of the session, superficial skin examination was also performed for each participant.

\section{Procedures for BEs}

In the control group, participants were given standard education around diabetes and foot care as routinely conducted at the PHC center. This includes dietary management, physical activities, medication management, foot hygiene, and ulcer prevention. In the intervention group, in addition to standard education, participants were showed how to perform routine BE as described by Allen in 1930 [14]. The exercise involves three basic maneuvers that can be performed independently as follows [14], [15], [16]:

1. Person lies supine with both legs raised gradually at an angle of 45-90 degrees for 1-3 min or until both legs appear pale, then

2. Sits down at the edge of the bed with both legs hanging over the side of the bed. This movement is then followed by dorsal flexion, plantar flexion, with lateral and medial flexion of the foot, respectively, for about 5-10 min or until both legs appear reddish
3. At the end of each exercise, participants were asked to cover both of their legs with a blanket for 3-5 min.

Each participant was requested to perform the maneuvers together then followed by one-on-one observation with the trainer. After the trainer felt satisfied with participants' performance, then participants were asked to perform the exercise at home 3 times a day in their convenient time with each session consisted of 3-4 cycles of the abovementioned maneuvers [5].

\section{Assessments}

The MNSI questionnaire used in this study was first described by Feldman et al. in 1994 [17]. It comprises two-step examination for diabetic neuropathy. The first step starts with a self-administered questionnaire comprises of 15 questions assessing sensation, numbness, lower leg symptoms, and general foot conditions. The questions require "yes/ no" responses with a "yes" response counted as 1 and "no" as 0 except for question numbers 7 and 13 which have reverse scoring. Question numbers 4 and 10 were not included in the scoring system. Question 4 was a measure circulation impairment and question 10 a measure of general asthenia and was not included in the published scoring algorithm [18]. Hence, the maximum score was 13 . The questionnaire was then followed by physical assessment assessing peripheral neurology function of participants' feet with range score of 1-10. The larger the MNSI score, the more severe the level of neuropathy. Then, an MNSI physical examination used a $128 \mathrm{~Hz}$ tuning fork test for vibration sensation and a $10 \mathrm{~g}$ monofilament test performed on both extremities of the feet as a screening for neuropathy. MNSI is available in Indonesian, the previous study had the results of validity and reliability with the construct validity test with $r$ count $0.371-0.765$ ( $r$ table 0.361 ) and the reliability test resulted in a Cronbach alpha value of 0.703 so that the instrument is said to be reliable if it has $r$ count $>0.6[19]$.

\section{Statistical analysis}

Data were processed in Microsoft Excel 2016 (Microsoft Inc., California, USA) and analyzed using SPSS v22 (SPSS Inc., Chicago, Illinois, USA). Participants' baseline demographics were expressed as either categorical data with frequency and percentage or continuous data with means and standard deviations. Continuous data were analyzed using the independent sample t-test while categorical data analyzed by applying the Fisher's exact test. The MNSI score differences between control and intervention groups were tested using either paired t-test or Wilcoxon signed-rank test for non-parametric data where applicable. We considered $p<0.05$ to reflect significant difference in the tests. 


\section{Sample size calculation}

Sample size calculation with a significance level of $95 \%$ and type I error of 0.05 ( $Z$ score 1.96 ) was used. Type 2 error of 0.1 ( $Z$ score 1.28 ) with standard deviation of 0.5 , mean difference from previous study of 0.4 [20] and anticipated $10 \%$ dropout rate resulted in a minimum sample size of 37 participants for each group of interest to be recruited.

\section{Ethics}

Ethics approval for the study was obtained from the Research Ethics Committee of the Faculty of Nursing Universitas Airlangga No. 1007/KEPK. All procedures involving human subjects were conducted in accordance to the WHO/CIOMS guidelines for research involving humans and the Declaration of Helsinki regarding human experimentation. Participants were provided with written informed consent before the commencement of their participation and signed the informed consent should they agree to participate.

\section{Results}

\section{Demographic data}

Between May and August 2018, we performed screening on 81 people with DM from three different districts in Surabaya city, Indonesia. At the end of 1-month follow-up, there were 40 participants who completed the schedule in the control group and 37 in the intervention group. Three participants in the intervention group did not complete the scheduled follow-up due to being away during the follow-up period (Figure 1).

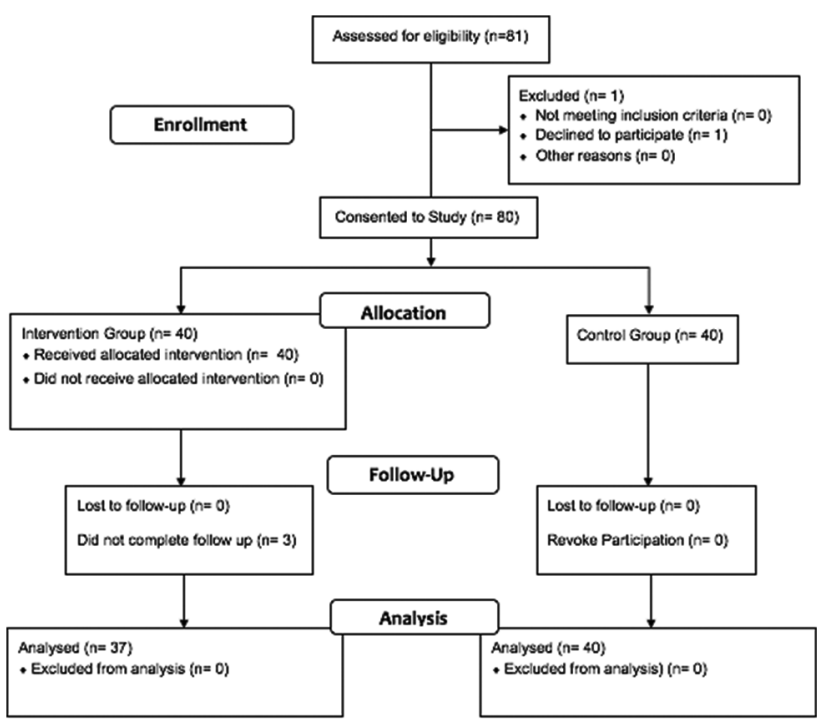

*). Recruitment time (May-August 2018)

Figure 1: Recruitment flow
Seventy-seven participants (14 males and 63 females) completed the study protocol. Participants' mean age was $58.2 \pm 7.2$ years with those in the control group being younger than the intervention group. Both groups were similarly matched in age, gender, occupation, educational level, and chronic comorbidities, except for age in years (Table 1).

Mean systolic and diastolic blood pressure for the intervention group was slightly higher than the control group, although both were not statistically significant. Participants' profiles for diabetes were also similar between the two groups as can be seen by duration of disease, medication, and random blood glucose taken at the beginning of the study (Table 1).

\section{Michigan neuropathy score}

All participants in both groups completed the MNSI questionnaire. Pre-test mean score for the control group was $3.9 \pm 1.6$ and was not significantly different to that of the intervention group $(3.8 \pm 1.7, p=0.561)$ at the beginning of the study. At the end of the follow-up period, however, the intervention group showed a significant decrease in mean score with absolute reduction of 1.0 points $(p=0.011)$. The opposite was found in the control group where post-test score was slightly higher than the initial MNSI score, although this was not statistically significant $(p=0.947)$ (Table 2).

The overall response for each question of the questionnaire is shown in Figure $2 a$ and $b$. The control group showed overlapping patterns between pre- and post-test mean scores. Most of the post-test mean

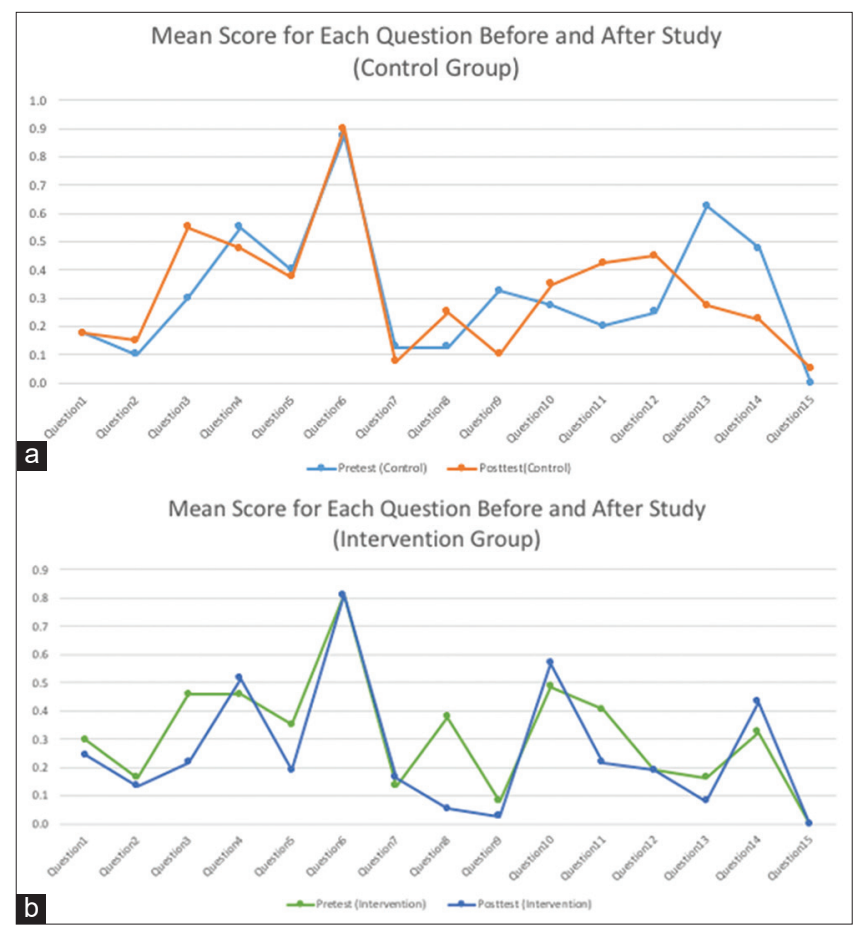

Figure 2: (a) Mean score each Michigan Neuropathy Screening Instrument (MNSI) questions before and after study (control). (b) Mean score each MNSI questions before and after study (intervention) 
Table 1: Patient characteristics

\begin{tabular}{|c|c|c|c|c|c|c|c|}
\hline Variable & $\begin{array}{l}\text { All participants } \\
(\mathrm{n}=77)\end{array}$ & $\%$ & $\begin{array}{l}\text { Control } \\
(n=40)\end{array}$ & $\%$ & $\begin{array}{l}\text { Intervention } \\
(n=37)\end{array}$ & $\%$ & $\mathrm{p}$ \\
\hline Age in year (Mean \pm SD) & $58.2 \pm 7.2$ & & $56.3 \pm 6.5$ & & $60.3 \pm 7.4$ & & 0.013 \\
\hline Gender & & & & & & & 0.076 \\
\hline Female & 63 & $82 \%$ & 36 & $90 \%$ & 27 & $73 \%$ & \\
\hline Male & 14 & $18 \%$ & 4 & $10 \%$ & 10 & $27 \%$ & \\
\hline Occupation & & & & & & & 0.092 \\
\hline Employed & 23 & $30 \%$ & 16 & $40 \%$ & 8 & $22 \%$ & \\
\hline Unemployed & 54 & $70 \%$ & 24 & $60 \%$ & 29 & $78 \%$ & \\
\hline Education level & & & & & & & 0.835 \\
\hline Primary/middle school & 52 & $68 \%$ & 27 & $68 \%$ & 25 & $68 \%$ & \\
\hline High school & 15 & $19 \%$ & 7 & $18 \%$ & 8 & $22 \%$ & \\
\hline No formal education & 10 & $13 \%$ & 6 & $15 \%$ & 4 & $11 \%$ & \\
\hline Active smoker & & & & & & & 0.667 \\
\hline Yes & 5 & $6 \%$ & 2 & $5 \%$ & 3 & $8 \%$ & \\
\hline No & 72 & $94 \%$ & 38 & $95 \%$ & 34 & $92 \%$ & \\
\hline SBP & $134.4 \pm 16.4$ & & $133.3 \pm 16.3$ & & $135.6 \pm 16.6$ & & 0.539 \\
\hline $\mathrm{SBP}>130$ & 50 & $65 \%$ & 25 & $63 \%$ & 25 & $68 \%$ & \\
\hline $\mathrm{SBP}<130$ & 27 & $35 \%$ & 15 & $38 \%$ & 12 & $32 \%$ & \\
\hline DBP & $79.7 \pm 9.7$ & & $77.8 \pm 8.2$ & & $81.6 \pm 10.8$ & & 0.083 \\
\hline $\mathrm{DBP}>85$ & 23 & $30 \%$ & 9 & $23 \%$ & 14 & $38 \%$ & \\
\hline $\mathrm{DBP}<85$ & 54 & $70 \%$ & 31 & $78 \%$ & 23 & $62 \%$ & \\
\hline BMI & $24.9 \pm 4.1$ & & $24.9 \pm 4.3$ & & $25.0 \pm 3.8$ & & 0.954 \\
\hline Underweight $(\mathrm{BMI}<18.5)$ & 4 & $5 \%$ & 4 & $10 \%$ & 0 & $0 \%$ & \\
\hline Normal (BMI 18.5-24.9) & 34 & $44 \%$ & 15 & $38 \%$ & 19 & $51 \%$ & \\
\hline Overweight (BMI > 25) & 39 & $51 \%$ & 21 & $53 \%$ & 18 & $49 \%$ & \\
\hline Duration of diabetes & $6.3 \pm 4.2$ & & $5.8 \pm 3.3$ & & $6.9 \pm 5.0$ & & 0.248 \\
\hline$\leq 3$ years & 22 & $29 \%$ & 11 & $28 \%$ & 11 & $30 \%$ & \\
\hline $4-7$ years & 29 & $38 \%$ & 17 & $43 \%$ & 12 & $32 \%$ & \\
\hline$\geq 8$ years & 26 & $34 \%$ & 12 & $30 \%$ & 14 & $38 \%$ & \\
\hline Random blood glucose & $177.8 \pm 79.0$ & & $168.4 \pm 8.4$ & & $188.0 \pm 76.1$ & & 0.280 \\
\hline$\leqq 200 \mathrm{mg} / \mathrm{dL}$ & 49 & $64 \%$ & 29 & $73 \%$ & 20 & $54 \%$ & \\
\hline$>200 \mathrm{mg} / \mathrm{dL}$ & 28 & $36 \%$ & 11 & $28 \%$ & 17 & $46 \%$ & \\
\hline \multicolumn{8}{|l|}{ Diabetes medication } \\
\hline Insulin & 7 & $9 \%$ & 1 & $3 \%$ & 6 & $16 \%$ & 0.051 \\
\hline Biguanide & 42 & $55 \%$ & 24 & $60 \%$ & 18 & $49 \%$ & 0.365 \\
\hline Sulfonylurea & 56 & $73 \%$ & 26 & $65 \%$ & 30 & $81 \%$ & 0.132 \\
\hline Combination & 37 & $48 \%$ & 19 & $48 \%$ & 18 & $49 \%$ & $>0.99$ \\
\hline Not routinely using medication & 16 & $21 \%$ & 9 & $23 \%$ & 7 & $19 \%$ & 0.783 \\
\hline
\end{tabular}

BMI: Body mass index, SBP: Systolic blood pressure, DBP: Diastolic blood pressure.

scores were less than except for question numbers $2,3,8,10,11$, and 12 that were lower than the initial responses. Different patterns can be seen in the intervention group (Figure 2b) where almost all the post-test mean scores for each question were lower than the pre-test.

Table 2: MNSI questionnaire between control and intervention groups

\begin{tabular}{|c|c|c|c|c|}
\hline MNSI score & Control group $(n=40)$ & $\mathrm{p}$ & Intervention group $(n=37)$ & 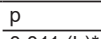 \\
\hline & & $0.947(a)$ & & $0.011(b)^{*}$ \\
\hline Pre-test & $3.9 \pm 1.6$ & & $3.8 \pm 1.7$ & \\
\hline Post-test & $4.0 \pm 1.9$ & & $2.8 \pm 2.2$ & \\
\hline
\end{tabular}

\section{Physical examination}

Tables 3 shows summary scores for physical examination for each of the participants' foot, conducted in accordance with the MNSI guideline. The control group had similar mean score for both feet at the beginning of the study. However, the score was not significantly different to those at the end of the follow-up period with $p=0.198$ and 0.613 for the right and left foot, respectively. On the other hand, the intervention group had significant decrease in mean score for the right and left foot after the 1-month routine BE $(p<0.05)$. Total scores for both feet also showed significant decrease for the intervention group from (mean $\pm \mathrm{SD}$ ) $1.8 \pm 1.4$ at the start to $1.3 \pm 1.1$ at the end of the study, but this was not seen in the control group (Table 3).
Table 3: MNSI physical examination between control and intervention groups

\begin{tabular}{|c|c|c|c|c|}
\hline $\begin{array}{l}\text { MNSI Physical } \\
\text { Exam }\end{array}$ & $\begin{array}{l}\text { Control group } \\
(n=40)\end{array}$ & $p$ & $\begin{array}{l}\text { Intervention } \\
\text { group }(n=37)\end{array}$ & $\mathrm{p}$ \\
\hline \multicolumn{5}{|l|}{ Right foot } \\
\hline Pre-test & $1.5 \pm 1.1$ & 0.198 (a) & $1.0 \pm 0.9$ & $0.005(a)^{\star}$ \\
\hline \multirow{2}{*}{\multicolumn{5}{|c|}{ Left foot }} \\
\hline & & & & \\
\hline Pre-test & $1.5 \pm 1.0$ & $0.613(a)$ & $0.8 \pm 0.9$ & $<0.001(\mathrm{a})^{\star}$ \\
\hline Post-test & $1.5 \pm 0.9$ & & $0.6 \pm 0.7$ & \\
\hline \multicolumn{5}{|c|}{ Both feet (average) } \\
\hline Pre-test & $1.5 \pm 0.9$ & 0.680 (a) & $0.9 \pm 0.7$ & $<0.001(\mathrm{a})^{\star}$ \\
\hline Post-test & $1.5 \pm 1.0$ & & $0.6 \pm 0.6$ & \\
\hline
\end{tabular}

\section{Discussion}

This study aimed to examine the short-term effect of routine BE to reduce the risk of neuropathy of people with DM in the community setting. In our results, two primary outcomes were: First, we found that participants with MNSI questionnaire (symptoms) scored lower and MNSI (physical examination) showed better results. This indicates that routine $B E$ could reduce the risk of the threat of the neuropathy patients with DM, either from the perspective measure (questionnaire) and objective one (physical examination), and second, $\mathrm{BE}$ is potential to be conducted on a larger community scale as a regular program.

The impact of $\mathrm{BE}$ on diabetic neuropathy could be seen in the decreased score on MNSI questionnaire after the intervention period. This was possibly due to the positive effect of $B E$ on improving peripheral circulation and subsequently improving 
neuropathy symptoms. The intervention also had an effect on improving signs of neuropathy. Based on the results of the MNSI questionnaire, most respondents tended to choose different answers on post-test which represented response of a decrease in symptoms and problems arising in the foot, such as pain, burning sensation, and pain in the legs on walking. The presence of the symptoms most likely to be the manifestation of peripheral neuropathy which, in turn, reduces the tactile and sensory function of lower extremity to trauma [21]. This condition would commonly result in ulcer of the legs that preclude diabetic foot ulcer [22].

$\mathrm{BE}$ may reduce the problems related to diabetes complications in the long term and improving the foot care, effectively preventing foot ulceration in people with DM [20]. In this study, participants were also given education about foot care in DM. They practiced $\mathrm{BE}$ at home and maintained ongoing foot care. The risk of recurrent foot ulceration could be reduced by specific self-intervention management including foot temperature measurement at home [10]. Giving them attention means directing the mind to something that needs to be learned and remembered [23].

In this study, on MNSI physical examination, the treatment group received good benefits from exercise performed in the previous month. These results suggested that intervention provided could improve circulation in the lower limbs (using gravity changes) so that there is a reduced risk of neuropathy in the group at high risk of developing of diabetic foot ulceration. Our study found that BE, combined with foot care education, significantly reduced neuropathy and alleviated discomfort in patients' feet. Second, this exercise required little cost and could be performed at low risk at home. Combined with foot care education, it significantly reduced peripheral vascular physiological indicators, diabetic peripheral neuropathy severity, and leg discomfort.

The maneuver of BE could improve the circulation of lower extremity in patients with DM through the sequential movement of the maneuver including the increase in cardiac output and arterial flow due to gravity and muscle contraction, and the use of flexor and extensor muscle of lower extremity to prevent joint stiffness [20]. BE may also stimulate the peripheral vascular system and improve the collateral circulation, gradually reduce pain of the lower extremity and reduce the risk amputation. These could lead to the improvement in quality of life of patients living with DM, especially those who are at risk of developing complications related neuropathy and peripheral vascular disease [11].

In our study, respondents both from control and intervention groups complained of pain in the lower extremity such as burning sensation on the feet, legs or thighs, pain on exercise, or performing daily activities at the beginning of participants' recruitment.
Duration and interval of the BE also play an important role in the improvement of peripheral vascular circulation. In this study, we administered the exercise on repeated cycle for each day. Each cycle took about nine minutes and was repeated 3 times a day. The benefit of regular exercise and physical activities has also demonstrated to reduce the diabetic foot and diabetes complications on lower extremities in several clinical trial studies [19].

\section{Limitations}

Several limitations in this study were that; first, the sample size was relatively small considering the number of people with diabetes in the populations, especially those who are in the setting of outpatient care. Second, the treatment allocation was not randomized that it may interfere with the causal relationships of the study. The problem was that the background characteristics such as socioeconomic status in each of the districts included in this study were very different. Thus, randomizing the treatment allocation may introduce another form of bias. Third, our recruitment process was performed together with routine community gathering in the public health center in the working hours, this may be one of the reasons behind the skewed gender distribution of participants as usually most of the male were working in the morning. In addition, researchers were relying on the self-reporting method from participants in informing the $\mathrm{BE}$ at home despite the gradual home visit and monitoring checklist in the study period. However, we believe that this intervention may improve the quality of life of people with DM, particularly due to its cost, feasibility, and practicability.

\section{Conclusion}

$\mathrm{BE}$ is a relatively simple physical activity that could feasibly performed routinely and larger community scale. It has beneficial effect on reducing the risk of the neuropathy of patients with DM which triggers diabetic foot ulcers. As an intervention that requires few resources and cost, it has potential benefits for the care of people with diabetes in developing countries.

\section{Acknowledgments}

We would like to thank you to the mayor government and the Head of the PHC in Surabaya city, Indonesia, who have helped and provided policies during the research process. 


\section{References}

1. Ministry of Health Indonesia. Riset Kesehatan Dasar 2018. Jakarta: Ministry of Health Indonesia; 2018.

2. International Diabetes Federation. IDF Diabetes Atlas. $8^{\text {th }}$ ed. Brussels, Belgium: International Diabetes Federation; 2017.

3. Ministry of Health Indonesia and HR and D Unit. Laporan Provinsi Jawa Timur Riset Kesehatan Dasar 2018 Basic Health Research East Java Province year 2018. Jakarta: Kementrian Kesehatan Republik Indonesia; 2018. https://doi.org/10.6066/ jtip.2013.24.2.121

4. Alzamora MT, Forés R, Baena-Díez JM, Pera G, Toran P, Sorribes $P$, et al. The peripheral arterial disease study (PERART/ARTPER): Prevalence and risk factors in the general population. BMC Public Health. 2010;10:38. https://doi. org/10.1186/1471-2458-10-38

PMid:20529387

5. Alvarsson A, Sandgren B, Wendel C, Alvarsson M, Brismar K. A retrospective analysis of amputation rates in diabetic patients: Can lower extremity amputations be further prevented? Cardiovasc Diabetol. 2012;11:18. https://doi. org/10.1186/1475-2840-11-18

PMid:22385577

6. Bharat Kotru SK. Intervention of diabetes foot care practices on the prevention of new diabetic foot ulcers in patients with Type 2 diabetes mellitus. J Diabetes Metab. 2015;6(2):1-6. https://doi. org/10.4172/2155-6156.1000494

7. Pratiwi IN, Pawanis Z, Hidayati L, Widyawati IY, Ni'mah L, Sukartini T, et al. The role of a healthy-eating educational module during Ramadan in a community health centre. J Diabetes Nurs. 2018;22(2):1-6.

8. BrunnerLS, Suddarth DS, Smeltzer SC. Brunner and Suddarth's Textbook of Medical-surgical Nursing. $11^{\text {th }}$ ed. Philadelphia, PA: Lippincott Williams \& Wilkins; 2008.

9. SchaperNC, Van Netten JJ, Apelqvist J, Hinchliffe RJ, Lipskyș BA, Board IE. Practical guidelines on the prevention and management of diabetic foot disease (IWGDF 2019 update). Diabetes Metab Res Rev. 2020;36(1):e3266. https:// doi.org/10.1002/dmrr.3266

PMid:32176447

10. van Netten JJ, Price PE, Lavery LA, Monteiro-Soares M, Rasmussen A, Jubiz $Y$, et al. Prevention of foot ulcers in the at-risk patient with diabetes: A systematic review. Diabetes Metab Res Rev. 2016;32(1):84-98. https://doi.org/10.1002/ dmrr.2701

PMid:26340966

11. Chang $C$, Chen $M$, Shen J, Bin Lin $Y$, Hsu W, Lin B. A quantitative real-time assessment of Buerger exercise on dorsal foot peripheral skin circulation in patients with diabetes foot. Medicine (Baltimore). 2016;95(46):e533. https://doi. org/10.1097/md.0000000000005334

PMid:27861361
12. Chang $\mathrm{CH}$, Peng YS, Chang CC, Chen MY. Useful screening tools for preventing foot problems of diabetics in rural areas: A cross-sectional study. BMC Public Health. 2013;13:612. https://doi.org/10.1186/1471-2458-13-612 PMid:23802741

13. Moghtaderi A, Bakhshipour A, Rashidi $H$. Validation of Michigan neuropathy screening instrument for diabetic peripheral neuropathy. Clin Neurol Neurosurg. 2006;108(5):477-81. https:// doi.org/10.1016/j.clineuro.2005.08.003 PMid:16150538

14. Allen AW. Recent advances in the treatment of circulatory disturbances of the extremities: Results obtained in the peripheral circulatory clinic of the Massachusetts general hospital. Ann Surg. 1930;92(5):931-46.

PMid:17866428

15. Wisham LH, Abramson AS, Ebel A. Value of exercise in peripheral arterial disease. J Am Med Assoc. 1953;153(1):10-2.

16. Kauffman TL, Barr JO, Moran M. Geriatric Rehabilitation Manual. $2^{\text {nd }}$ ed. Edinburgh: Churchill Livingstone; 2007.

17. Feldman EL, Stevens MJ, Thomas PK, Brown MB, Canal N, Greene DA. A practical two-step quantitative clinical and electrophysiological assessment for the diagnosis and staging of diabetic neuropathy. Diabetes Care. 1994;17(11):1281-9. https://doi.org/10.2337/diacare.17.11.1281

PMid:7821168

18. Herman WH, Pop-Busui R, Braffett BH, Martin CL, Cleary PA, Albers JW, et al. Use of the Michigan neuropathy screening instrument as a measure of distal symmetrical peripheral neuropathy in Type 1 diabetes: Results from the diabetes control and complications trial/epidemiology of diabetes interventions and complications. Diabet Med. 2012;29(7):937-44. https://doi. org/10.1111/j.1464-5491.2012.03644.x

19. Pinzon RT, Sanyasi RD. The improvement of neuropathic symptoms after Vitamin B combination administration in diabetic neuropathy patients. Pharm J Indones. 2018;15(2):231-42.

20. Chang CF, Chang CC, Hwang SL, Chen MY. Effects of buerger exercise combined health-promoting program on peripheral neurovasculopathy among community residents at high risk for diabetic foot ulceration. Worldviews Evid Based Nurs. 2015;12(3):145-53. https://doi.org/10.1111/wvn.12091 PMid:25963925

21. Sukartini $\mathrm{T}$, Asmoro $\mathrm{CP}$, Alifah $\mathrm{PN}$. The influence of diabetic foot exercise in sensory peripheral neuropathy with monofilament test on diabetes mellitus clients. J Ners. 2019;14(3):340-4. https://doi.org/10.20473/jn.v14i3.17263

22. Widyawati IY, Irawaty D, Sabri L. Active lower range of motion reduce the sign and symptom of diabetic neuropathy. J Ners. 2010;5(2):107-17.

23. Indarwati R, Pratiwi IN, Yuniarsih N. Playing cards using the 'tepuk nyamuk' method improves cognitive function and social interaction in the elderly. Indian J. Public Health Res Dev. 2019;10(8):2575. https://doi.org/10.5958/0976-5506.2019.02255.1 